\title{
Research on the Cross-cultural Communication Strategy of Li Ziqi's Short Videos
}

\author{
Lin Zhang ${ }^{1, *}$
}

\author{
${ }^{1}$ School of Media and Technology, Liaocheng University, Liaocheng, Shandong, China \\ *Corresponding author. Email: 16500901@qq.com.
}

\begin{abstract}
This article takes Li Ziqi's short video as a successful case of Chinese cultural short video, and analyzes the reasons why it attracts Chinese and foreign audiences from the perspective of crosscultural communication. According to the research, the communication content of Li Ziqi's short videos conforms to the cultural prototype common to the world; the communication symbol adopts personalized national expression; the communication discourse abandons the traditional grand narrative and adopts the modern aesthetic narrative; the communication effect satisfies the value recognition of the audience. The above four aspects together constitute the cross-cultural communication strategy of Li Ziqi's short videos, which can provide reference and reference for the cross-cultural communication of Chinese culture in the short video era.
\end{abstract}

\section{Keywords: Li Ziqi, cultural archetype, infinitesimal narrative, cross-cultural communication}

\section{INTRODUCTION}

The short videos of Li Ziqi appeared in 2015. The earliest content was mainly short videos of ancient Chinese cuisine, such as "Lanzhou Beef Noodle", "Cherry Wine", etc. Later, the theme was expanded to local beauty, traditional skills, etc., attracting a large number of Chinese and foreign audiences, and $\mathrm{Li}$ Ziqi became one of the representative figures of Chinese cultural short videos. With the continuous expansion of the influence of Li Ziqi's short videos, academic research on Li Ziqi's short videos has gradually increased. Taking China CNKI's (China Network Knowledge Infrastructure) journal retrieval as an example, searching for "Li Ziqi" as the subject, the researchers obtained 76 research papers. 74 of them are concentrated in 2019 to present. From this, it can be seen that Li Ziqi, as an excellent case in the short video era, has become a representative cultural communication phenomenon, including academic interpretations that conform to the concept of national cultural development, and has the value of providing reference for cross-cultural communication in the mobile Internet era. Chinese scholar Lu Gaofeng pointed out that Li Ziqi's overseas popularity has given people new enlightenment on how Chinese culture can go out: telling Chinese stories and shaping a good national

*Fund: Shandong Province Art Science Key Project: Research on the National Subjectivity of Domestic Animation Movies from the Perspective of Narratology (ZD202008134). image not only depends on the publicity of the national mainstream media, but also pays attention to "silent" type of "invisible propaganda". The host Bai Yansong also gave positive comments and positive recognition to the "Li Ziqi Phenomenon" in the "Newsweek" program of CCTV News Channel in December 2019, and affirmed her practice value of "telling Chinese stories and showing China's image". "Is Li Ziqi cultural output?" Or it no longer constitutes a hot spot of public opinion. Taking the strategy of cross-cultural expression as the starting point, investigating how the short videos of folklore represented by $\mathrm{Li}$ Ziqi realize cross-cultural communication is of great significance and value to the cultural output and dissemination of the short video era.

In the 1930s, Heidegger predicted the arrival of the "image age", proposed the concept of "the world is grasped as an image", and regarded "the world as an image and people as the subject" as two important process that marks modernity. Based on this, people can observe the short video communication in the we-media era. Based on the cultural foundation that highlights the visibility and visual pleasure, with its small space, fine content, strong interaction, and high viscosity, it has become an effective form of discourse suitable for social media communication in the mobile Internet era. In this context, only things that are grasped as images and widely disseminated by the audiences are "things full of power and influence, and invisible 
things are inevitably rejected." Invisible means that the audiences cannot see it. It has two levels of meaning: first, content that has not been imaged or videoized cannot be seen by the audience; second, although it is imaged or videoized, it is not the content accepted by the audience, which cannot be seen either. Therefore, in the context of globalization, using short videos as the carrier, spreading Chinese culture and telling Chinese stories in a way that audiences love to hear. Being "seen" by the world audience has become an important responsibility and mission of crosscultural communication in the context of short videos. The short videos of traditional Chinese culture represented by Li Ziqi are a successful case of cross-cultural communication.

\section{LI ZIQI'S SHORT VIDEO COMMUNICATION STRATEGY}

Chinese scholar Zhao Yiheng defines culture as "the total collection of all meaningful activities in a society", and the carrier of meaning expression is the symbol. Chinese culture, as a practice of symbolic ideology that occurs in Chinese society, must have the commonality of world culture in the process of external dissemination, break through the ideographic limitations of national culture, and avoid cultural discounts and "non-communication" phenomena in cross-cultural communication. It is also necessary to emphasize the individuality of the national culture and seek the proper expression of the local culture in order to form a dialogue with the world's culture, and achieve "the beauty of each, and the beauty of the same."

\section{A. Communication content and cultural prototype}

The French structuralist mythologist Levi Strauss proposed on the basis of linguistics and psychoanalysis that human beings have a common survival contradiction, which is contained in the myths of all nations in the world, forming a common cultural psychology. Dreams are personal myths, and myths are collective dreams. As a product of collective unconsciousness, myths seem to be rich in imagination and illogical, but they are the product of human rational thinking with a stable dual structure that can explain the common human psychology and mode of thinking. Although the myth stories are constantly changing, the theme remains the same forever, hidden deep in the narrative of the stories. Therefore, Levi Strauss believes that through mythological research, people can observe the cultural commonalities of all nations in the world, which in turn constitutes a common psychological structure and becomes the basis of cross-cultural communication. This cultural commonality is the unity of opposites between culture and nature in the process of human development. In modern society, it is manifested as a binary opposition between modern people's dependence on industrial and commercial civilization and the yearning to return to nature. $\mathrm{Li}$ Ziqi's short videos satisfy human's common imagination of nature. The cultural content presented in the videos is separated from modern industrial production lines and uses traditional hand-made methods to restore the harmonious symbiosis relationship between man and nature in the pre-industrial era, becoming a kind of spiritual comfort that helps the audiences to imaginatively mediate the unresolved problems and contradictions in reality. On April 23, Li Ziqi appeared in the "New York Times" and was hailed as the idyllic "princess" during the isolation period. In this special period, the fragility of the consumer society industry supply chain was exposed. And Li Ziqi's "pastoral and pastoral life in which everything is done personally is aspirational and has become a reliable source of relief and comfort."

\section{B. Communication symbols and ethnic expression}

Another important feature of culture is ethnicity and locality. Different ethnic cultures promote the richness and diversity of world culture and constitute an exotic landscape for viewing. Short video, as a dynamic image, has similar artistic psychology to movies. As a visual-led ideographic medium, the "spectacle" of vision has become the distinctive feature since the birth of the film. Presenting exotic landscapes and expressing the culture of others, the film has become a "dream factory" for global audiences. If it can be said that in the early stage of film development in the early 20th century, constrained by the uneven development of the world's political structure, China appeared as an alienated "other" image in the Western perspective, then with the enhancement of China's comprehensive strength and the promotion of its international status, it has become the common expectation of all countries in the world to show the beautiful characteristics of the Chinese nation from both material and spiritual culture. The natural scenery and pastoral work presented by $\mathrm{Li}$ Ziqi's short videos are full of aesthetic characteristics with Chinese characteristics and reflect the organic combination of various cultural elements. Taking the "pen, ink, paper and inkstone" uploaded in March 2019 as an example, the video completely restores the production process of the four treasures of Chinese study. Pen, ink, paper and inkstone are material culture, and their production process can be regarded as a normative culture. Not only for foreign audiences, but even for Chinese audiences, traditional crafts, as intangible cultural heritage, are also presented as a visual wonder. Papermaking is one of China's four great inventions and a treasure of world culture. Duan inkstone is not only a material culture, but also includes the art of seal cutting. It is the embodiment of the 
combination of the practicality and artistry of the traditional Chinese literati who appreciate the bamboo's character. Since ancient times, bamboo has been called a gentleman, a symbol of integrity and mind. At the same time, bamboo is also a symbol of peace, strength, and longevity. Bamboo is used as a painting to form the traditional spiritual culture of the Chinese nation. This video is 11 minutes and 40 seconds long, but its production process took two years. It started in the autumn of 2017 and was completed in the spring of 2019. The total number of views exceeded 10 million. It is still being followed and appreciated. Some foreign netizens left a message saying, "This is the best video during the quarantine period, which makes people feel calm."

\section{Communication discourse and infinitesimal narrative}

Compared with the grand narrative, the infinitesimal narrative has got rid of the ideological discourse system, emphasized the common people's perspective of secularization, and expressed the deep value of Chinese national culture through the daily life that the audiences love to hear, and has the characteristics of lifelization, dramatization, and trivialization. British Marxist cultural critic Raymond Williams believes that culture is an overall way of life. Li Ziqi took daily diet, work, and leisure as the starting point, with the help of aesthetic lens language, and selectively described the rural lifestyle with Chinese characteristics in detail. She organically unified practical value and aesthetic value, becoming the representative of Chinese classical pastoral culture. In the crosscultural communication of cultural symbols, the intertextuality between local and foreign cultures also constitutes an important factor that affects the effect of communication. The American scholar Blaisler believes that "the meaning of the text exists in the code that the reader has mastered before picking up the actual text." Therefore, the understanding of Chinese culture by readers of different cultures is based on their own understanding as the background and intertextual interpretation. The cultural imagery of the common structure of space, image, and objects forms intertextuality with Chinese texts familiar to Western audiences, and interprets the Chinese national symbol ideology that conforms to a global perspective. The distant mountains, the village, the countryside, and the small farmhouses together constitute the narrative space environment. The white clouds drifting leisurely over the empty shots of the mountains give the picture a remote artistic conception like a paradise. Li Ziqi, dressed in common clothes, works in the fields that change throughout the seasons. In spring, she plants seedlings in rice fields and digs bamboo shoots in bamboo forests; in summer, she picks lotus roots in lotus ponds and chestnuts in mountain forests; in autumn she harvests purple sweet potatoes, soybeans and peanuts, eats persimmons, and dries millet; In winter, shei wraps in a piece of silver, wears a big cloak, making a bowl of hot Buddha jumping over the wall. Planting in spring, harvesting in autumn, weeding in summer, and storing in winter, Li Ziqi presents Chinese people's unique perception of the world and life from daily life. From sowing, to harvesting, to the production of daily diet and daily necessities that adapt to the season, with the beautiful lens language and ancient music, daily life has a ritualistic meaning, and everyday objects have been given the value of love and respect, which has become an effective channel to glimpse the Chinese civilization and the spirit of Chinese culture.

\section{Communication effect and value recognition}

Any cultural ideographic activity is carried out in the dual-axis relationship between the aggregation axis and the combined axis. Although a symbolic ideogram logically has a dual-axis operation sequence, in the actual selection, they are carried out almost at the same time and follow a certain meaning standard. After the text is completed, the aggregation axis is hidden, and the combination axis appears to become an aggregation projection. The wide aggregation segment forms a dense projection of the combined unit, which helps to form a diverse style of text. As a kind of ideographic text, short videos also follow the twoaxis principle. The narrative structure is a combination of various elements, and each element is the result of aggregate selection. The width or narrowness of the aggregate segment behind each component in the narrative is projected into the composition unit of the text, which affects the style of the text. "The width leads to diversification of styles and more unexpected arrangements in the combination." As the main body of the short video narration, Li Ziqi broadens the aggregation section of the main unit in the process of external cultural dissemination, and becomes a successful selection case in the biaxial operation. Using international media to tell Chinese stories and spread Chinese excellent culture is not only the focus of national propaganda and ideological work, but also an effective means to shape the country's image and break the hegemony of Western media. Since 2011, China has successively launched cultural propaganda films such as "Chinese National Image Film - Characters", "Cultural China", "A Bite of China", "China Enters a New Era", "China One Minute", etc. While widely praised and concerned, the problem of too single propaganda subject has gradually emerged. The country has become the subject of mainstream narrative, carrying the ideological characteristics of grand narrative. Against this background, Li Ziqi, as a young 
woman in modern China, dressed in traditional costumes, showing ancient customs and food, her independent female posture and naturalistic life have all succeeded in inquiring the psychological identity of the modern public. In the "Life of Cotton" short video, some foreign netizens left a message: "I hope everyone will collectively petition to let Disney create a princess character based on $\mathrm{Li}$ Ziqi, a princess who does not need Prince Charming to redeem and can survive independently." The identification with Li Ziqi can be seen from this. As a woman recognized by modern culture and as a narrator of Chinese culture, $\mathrm{Li}$ Ziqi broadens the choice of cultural communication subjects, thus making cultural narratives richer and more diverse, and has a positive impact on the effect of China's cultural communication to foreign countries.

\section{CONCLUSION}

As of May 21, 2020, Li Ziqi's Youtube subscriptions reached 10.4 million, and the views of popular videos reached more than 20 million, becoming the best footnote to the "Li Ziqi phenomenon". The era of short video is also the era of attention economy, emphasizing fast-paced and eye-catching, but Li Ziqi has completed a cultural breakthrough across the world in a slow-paced daily life among many short video products. Based on the common psychological structure of world culture, it presents the individualized expression of national culture, adopts the secular narrative that audiences love to see, and tells the vivid and rich traditional culture of China from the perspective of women. Li Ziqi's success may not be replicated, but the successful cases she provides can provide useful reference for how to tell Chinese stories well in the short video era.

\section{References}

[1] Lu Gaofeng, The Enlightenment of Li Ziqi's Overseas Popularity [J]. Youth Journalist, 2019 (12). (in Chinese)

[2] Zhao Yiheng, Cultural Semiotics [M]. Chinese Federation of Literary and Art Circles Publishing House, 1990, p89. (in Chinese)

[3] Charles E. Bressler, Literary Criticism [M]. Zhao Yong, Li Sha, Chang Peijie, etc. trans. China Renmin University Press, 2015, p130. (in Chinese)

[4] Zhao Yiheng, Semiotics Principles and Deduction [M]. Nanjing University Press, 2016, p160. (in Chinese)

[5] Zhou Xian, The Turn of Visual Culture [M]. Peking University Press, 2008, p7. (in Chinese)

[6] Zhu Liyuan, Contemporary Western Literary Theory [M]. East China Normal University Press, 2014, p216. (in Chinese) 